\title{
Five Principles for Digital Service Innovation in Social Care
}

\author{
Gitte Tjørnehøj \\ Aalborg University, \\ Department of Political Science, \\ Centre for IS Management \\ gti@dps.aau.dk
}

\author{
Hanne Westh Nicolajsen \\ IT University Copenhagen, \\ Department of BusinessIT, \\ Copenhagen, Denmark \\ hwni@itu.dk
}

\begin{abstract}
Digitalization in the public sector is growing to also include areas such as social care. We investigate the digital service innovation process within home care services in a Danish municipality. Inspired by theory on social materiality, we argue for an approach to digital service innovation within social care as an ongoing and entangled development of human and technological resources. We take an abductive approach as we combine theory on socialmateriality and digital service innovation with empirical insights. Based in this, we propose five principles of importance for successful digital service innovation in social care: 1) mutual adaption; 2) piloting; 3) empowered; 4) situated re-innovation, and 5) continuous innovation.
\end{abstract}

\section{Introduction}

The public sector explores digital service innovation to overcome cross-pressure of cutbacks and the growing need for service [1]. Technological progress has given new openings [2] to digitalizing existing services in order to develop new types of services [3] [4]. The particular case of home care involves telemedicine, which as a social service is highly complex because of the combination of technology-based services and person-oriented, nontechnological services, typically delivered over long service periods [5]. In general, innovation in the public sector is demanding, as public sector organizations are bureaucratic by design [6] and less prone to change.

New capabilities are needed to perform digital service innovation in the public sector, especially within service architectures, co-creation processes, and privacy/equity policies [4]. Lusch \& Nambisan [7] argue the necessity for extended ecosystems using emerging actor-to-actor structures for integration of resources in co-creation of services and for service platforms in order to enhance service exchanges.

In line, Bygstad \& Lanestedt [8] suggest that successful information and communication technology-based service innovation within public projects requires strong integration of the service provider and the external users and that alliances with key stakeholders are more important than focus on time, cost, and quality.

Service innovation in the public sector can be described as new or improved services that may also involve service delivery innovation and require organizational or administrative innovation. Likewise, conceptual innovation, policy innovation, or systemic innovation all targeting deeper aspects of an organization may be necessary [9]. Public service innovation is thus a complex matter involving most levels, many parties, and a diversity of aspects.

Orlikowski \& Scott [10] argue that information technology is best described as socio-material assemblages inextricably linking the technical and the social. In a recent paper, they argue that a sociomaterial approach challenges us to reframe our research on service innovation [11]. We contend that this view on digital service innovation will be fruitful in order to understand the highly complex phenomenon of social service innovation (in social care). As social services involve diverse personal, physical, and intimate services to citizens, innovations will shape and extend socio-material assemblages that are diverse and unpredictable [12].

Our research question is:

How can we understand public digital service innovation in complex social situations through the lens of social-material assemblages?

This paper discusses how innovation towards new useful socio-material assemblages in social service can be understood and practiced. We uncover essential challenges and opportunities and we suggest five principles for digital service innovation towards useful assemblages in social services.

First, we present the case of tele-visits and explain our research approach before we give an account of social materiality and innovation. Based on this, the principles for digital service innovation are developed and illustrated empirically. Lastly, we discuss the implications of the developed principles and the theoretical contribution. 


\section{Case introduction: Virtual home and health care in Viborg municipality}

Viborg municipality has 100,000 inhabitants, 5,900 employees, and covers $1,500 \mathrm{~km} 2$. It is known to be on the forefront of digitalization and for its intense collaboration with many stakeholders in these efforts. Due to the cross-pressure, management of the home care division constantly looks for opportunities for digital service innovation. In this case, they were inspired by seeing a tele-care product designed to reduce hospitalization of citizens with chronic obstructive pulmonary disease (COPD). The municipality and the technology vendor (Viewcare) joined in a public-private innovation partnership to transform the COPD service system into a useful and integrated service system in home care practices.

During an experimental pilot project taking place in one of the 10 home care centers, the technology and services evolved to support the carers' practices. The practitioners participated actively in the full circles of idea generation, design, development, and evaluation of the emerging digital services, together with a project manager from the internal innovation center and the technology provider. The pilot addressed both technical aspect such as data privacy and social aspects such as involving citizens.

The resulting digital service permitted carers to pay virtual visits to the citizens from the home care centers and thus reduced the time consumption for visits and commuting. Also, but unexpectedly, the system improved the well-being of citizens by increased discretion, flexibility, and immediate and attentive contact. The visits were useful for medication supervision and other non-physical services. Despite the distance in the tele-visit, both the citizens and the carers experienced real and attentive presence. This was reassuring for citizens, while carers had a feel for the well-being of citizens, which is very important to the carers as they feel personally committed to "their" citizens.

At the end of the pilot project, management wondered how to roll tele-visit out successfully. Advised by the researchers and understanding the diversity of the demography, geography, culture, etc. of the home care centers, they decided to carry out a lightweight pilot in each center. They combined traditional roll-out practices and re-innovation allowing the centers to adapt the system into their practices to some extent. At kick off workshops in each center, the new service was introduced. The technology provider presented the tool and colleague from the pilot center introduced the service system. Following, carers of the center were asked to engage in idea generation and initial try-outs. In addition, each center had appointed and trained a super-user to help and push her colleagues and to handle the technology.

In some centers, this approach triggered willingness to try the technology whereas in others the skeptical employees were decisive. Center managers were obliged to promote tele-visits and report progress. Rather quickly it was clear that the goals for tele-visits in the business case were not realistic.

As the project continued, additional benefits were realized. The tele-visit service served as a lifeline while citizens became self-reliant, and as carers became familiar with the system, new uses emerged (e.g., extensive use in internal collaborations such as "having" a nurse at the morning meeting, without him or her coming in or calling the nurse together with the citizen in order to provide correct care). Thus, the project manager arranged monthly workshops with the super-users to nurture their innovative mindset and to detect and spread new innovations.

\section{Socio-materiality and digital service innovation}

To achieve deep insight into and theorize about the mechanisms of digital service innovation, we apply the theory of socio-materiality as it permits understanding the complex assemblages of digital services. Our socio-material thinking is based on a long discourse on the relation between information technology and the social [13].

Early theory on information technology tends to emphasize either the technological [14] or the social [15]. More recent research assumes information technology, humans, and organizations form mutually dependent assemblages, shaping each other through ongoing interaction [13]. However, Orlikowski contends [13, p.137] this understanding is not sufficient "as contemporary forms of technology and organizing are increasingly understood to be mutable, fluid, temporary, interconnected and dispersed."

We find this perspective of inherent entanglement of the social and material appropriate for investigating digital service innovation in its full complexity. The theory is suited to capturing how technology is intrinsic to all actions and relations in organizational life [10] and in the "increasingly complex materiality of every-day IS-mediated work practices" [16]. From this perspective, analyzing material and social elements as separate may lead to misinterpretations of innovation practice [17]. 
The material, including information technology, and the social fuse together into practices [18]. A useful fusion will be a situated, meaningful assemblage of the available social and material resources that are beneficial in that concrete situation. However, this will be difficult to predict as boundaries and relations between information technology and the social are seen as enacted in practice. Thus, focusing on fusing the social, material, and information technology fittingly is vital in innovation.

This notion matches the theory of digital services innovation, but emphasizes the situatedness, the continued emergence, and in the fusion of the assemblages the material and the social are equally acting.

\section{Research approach}

This research is based on our assumption that the theory of socio-materiality can unveil important aspects of innovation (i.e., having strong causal power) [19][20], as it is suggested to be a strong mechanism behind observed use and effects of information technology [13]. The resulting principles for digital service innovation were developed iteratively between studying the case and theoretical reasoning based on the theory of socio-material assemblages. The initial idea was that if technology is inherently socio-material then an information system only makes sense when situated. Thus, one cannot meaningfully roll-out an information system without allowing for mutual adaption between the existing and the new (see principle \#1 in Section 5.1, which is primarily based on theoretically reasoning). As new technology is malleable and flexible, this is possible. In line with this rolling out, information systems need to be a re-innovation process for the technology to become situated. This idea was suggested to the managers of the case and apparently it made sense to them, as they designed a new roll-out process based on the theoretically argued idea. We studied the rollout process and its effect, getting important empirical feedback that allowed us to refine our ideas and eventually phrase the principles. Principles \#5 and \#6 are theoretically based and supported by the empirical findings. Because the roll-out performed as re-innovation was meaningful for the practitioners, it confirms the causal power of the concepts. In this article, we argue the principles theoretically (see Section 4) before illustrating the principles as they play out in the case.

We entered the case when the pilot was over and the managers planned the roll-out. Thus, the empirical data of the initiating negotiations and the pilot project are retrospective and retrieved through 21 semi-structured interviews of approximately 1 hour. We interviewed a broad range of involved actors: the initiator, the central manager of the rollout, carers participating in the pilot, managers and carers from other home care groups, and managers and employees from the vendor. We asked about the respondents' experiences with and view of: 1) the new practice of tele-visiting, 2) the innovation and roll-out processes, and 3) the tele-visit information system itself. The interviews were recorded and transcribed.

In our data analysis, we noted both aspects mentioned by interviewees and aspects that we found interesting when comparing to traditional theory of organizational implementation. From this data analysis, the principles of pilot innovation were developed (See principles \#2 and \#3). This piece of research thus takes an abductive approach [19][20]. We are combining insight from our case study with theory on social-materiality to investigate elements. The principles were discussed with the mangers of the project and presented to top management of the municipality and the vendor. The paper is reported from the viewpoint of the municipality.

\section{Arguing the principles of digital service innovation}

This section presents the theoretical arguments behind the suggested principles of digital service innovation as socio-material practice. However, to phrase and theoretically base the individual principle we also draw on theory from participatory design, service design, service innovation, etc.

Table 1. The Principles of Digital Service Innovation in Social Care through the Lens of Social-Materiality

\begin{tabular}{|c|c|c|}
\hline $\mathrm{Nr}$. & The principle of ... & Explanation \\
\hline$\# 1$ & $\begin{array}{l}\text {.. mutual adaption } \\
\text { between the social } \\
\text { and material. }\end{array}$ & $\begin{array}{l}\text { The existing assemblage need not carry } \\
\text { the full adaption as information } \\
\text { technology has become malleable. }\end{array}$ \\
\hline \#2 & $\begin{array}{l}\text {.. piloting the } \\
\text { creation of deep } \\
\text { insight in practice, } \\
\text { technology, and } \\
\text { the emergent } \\
\text { assemblage. }\end{array}$ & $\begin{array}{l}\text { Deep learning is crucial in innovation. } \\
\text { Collaborating parties respectively skilled } \\
\text { in technology and practice provide basic } \\
\text { knowledge. Learning is enabled through } \\
\text { iterative, practice-embedded, and } \\
\text { experimental innovation. }\end{array}$ \\
\hline \#3 & $\begin{array}{l}\text {...empowered, } \\
\text { user-driven, and } \\
\text { participatory } \\
\text { innovation. }\end{array}$ & $\begin{array}{l}\text { The practitioners know what is and have } \\
\text { the expertise to suggest and evaluate } \\
\text { what may be. Thus, they should be } \\
\text { empowered to drive the innovation. }\end{array}$ \\
\hline \#4 & $\begin{array}{l}\ldots \text { rolling out as } \\
\text { situated re- }\end{array}$ & $\begin{array}{l}\text { Socio-material assemblies all differ in } \\
\text { aspect such as place, time, and actors. }\end{array}$ \\
\hline
\end{tabular}




\begin{tabular}{|l|l|l|}
\hline & innovation. & $\begin{array}{l}\text { Thus, useful assemblages need to be } \\
\text { situated. }\end{array}$ \\
\hline$\# 5$ & $\begin{array}{l}\text {.. continuous } \\
\text { innovation } \text { will } \\
\text { enhance benefits. }\end{array}$ & $\begin{array}{l}\text { Continuously being open to and } \\
\text { exploring opportunities enhances } \\
\text { benefits-realization through exploitation. }\end{array}$ \\
\hline
\end{tabular}

\subsection{The principle of mutual adaption}

If innovation is theorized as socio-material practice, innovation must mean introducing services into an existing socio-material assemblage that will inevitably change. Introducing standardized services fosters risk of useless assemblages, as the existing assemblages must fully assign to the system, which may compromise valuable practice. On the other hand, malleable information systems increase the chance of achieving useful practices [10] through mutual adaption. This scenario has become realistic, as newer information technology offers incremental, component-based development and flexible platforms sufficient to support (continued) innovation [7][3] of socio-material assemblages.

We suggest that the flexibility of the information technology plays a crucial role for useful innovation of the socio-material assemblages (e.g., in digital service innovation). Therefore, innovation processes need to be organized and carried out to ensure mutual adaption of new services and the existing assemblage. This leads to the principal of mutual adaption between the social and material in emerging digital service assemblages (\#1; see table $1)$.

\subsection{The principle of piloting}

In participatory design theory, deep insight into users' practice, the technological potential, and the emergent information system are vital in designing useful systems [21]. This fits the socio-material understanding perfectly as it suggests basing design on knowledge of both the social and technical - the existing and the new. Bringing the needed knowledge into play demands close collaboration between the parties holding insights in, respectively, practice and technology - in this case the carer and the vendor. Acquiring the needed technological knowledge either in-house or through external collaboration is central to digital service innovation [4][22]. However, building the insights needed to suggest and design a useful new fusion demands mutual learning through an experimental and iterative innovation process, exploring and exploiting the potential of the technology and the socio-material.

To learn deeply enough to evaluate suggested new digital services, these experiments must be embedded in the existing socio-material assemblages (practices) as only in practice can the full complexity and situatedness be understood. The often-used laboratory settings are missing out on important knowledge [8][3]. We suggest that embedding innovation in the existing socio-material assemblages will enhance the fusion of the social and the new information technology into new useful practices.

This leads to the principle of piloting, creating deep insight in practice, technology, and the emergent assemblage (\#2; see table 1).

\subsection{The principle of empowerment}

Only actors of practice possess deep knowledge of the existing socio-material assemblage [23]. As work becomes gradually more specialized, the practitioners increasingly hold knowledge that their managers do not [9]. They are the ones who know what is, and they have the expertise to suggest and evaluate what may be [23]. Thus, traditional user involvement by representation, as informants or testers of the experiments, will be inadequate. Empowering the practitioners as equal partners participating in, and at best driving idea generation, design, testing, and decisions in the experiments, will bring their expertise into play, thereby enhancing the chance of developing a useful (socio-material assemblage) practice [8]. As an important side effect, this empowerment and influence on their work is likely to create commitment and engagement, which will be helpful during roll-out. This leads to the principle of empowered, user driven and participatory innovation (\#3; see table 1).

\subsection{The principle of situated re-innovation}

Above we argue that piloting according to the presented principles will set the route towards new useful socio-material assemblages, ready for roll-out. However, if socio-materiality is useful for understanding practice, then the full assemblage must adjust whenever there is any social or material change. When rolling out a socio-material assemblage, the social and the material of the existing assemblage will be considerably different from the pilot in socio-material aspects such as geography, actors, culture, and management. Unless the assemblages are very simple and stable across the organization, the receiving assemblages will often find the system unfitting of their practice [9]. The result is often lack of commitment or even resistance.

Rolling out the socio-material assemblage of the pilot can theoretically be argued to be impossible and in practice even trying is counterproductive. It will 
involve probably harmful attempts to standardize all locations, cultures, etc. of the organization, which creates the above-mentioned risks of compromising useful practice. The receiving practitioners may invent work-arounds or other alternative roads to make their own meaningful assemblages, forcing the technology to adapt [9].

Activities openly focusing on creating a useful new assemblage in the receiving locality may prevent issues. In piloting, as above, practitioners are free to design adaptions to the technology according to their wish for new practices. Receiving practitioners have the same needs for adaption. If the receivers were allowed this free mutual adaption, then it is more likely that the new assemblages would be useful locally.

However, realities of technology, economy, quality requirements, documentation, and political will set limits to what is possible. A significant challenge is balancing employees' personal wishes and the requirements from the organization. Consequently, the organization will act as part of the existing assemblage, but it is likely to promote standardization and homogeneity. This is the wellknown tension of structural flexibility and structural integrity [7]. Management is likely to resist the loss of control that can follow widespread free innovation. They do, after all, invest in the innovation in order to reach their goals of beneficial digitalization. A pilot project is controllable in the sense that it has a deadline and a manageable size, and that management has the final word. This management need for control through uniformity is counterproductive as is evident in the reasoning above. Also, Ciborra [23] suggests management should let go, as only employees possess sufficient knowledge. He urges organizations to learn how to exploit the drifting of practices. We suggest that rollout should be organized as re-innovation in all the receiving socio-material assemblages within, but pushing the barriers to their limit. Approving this takes courageous top-management and very skilled innovation and change managers.

Being empowered to influence change in one's practice when a system is introduced, and being asked to contribute with new ideas, goes some of the way to re-innovating a situated innovation. It will help practitioners to make sense of the new practices, to ask all their questions, and to be inventive about their local practice within the project frame. For many, this involvement will suffice, as it is likely that the practices in the centers have similarities that the digital service will be appropriate for in most tasks.

We suggest creating the necessary knowledge for designing useful digital services through pilot projects and experiments, thereby ensuring situated innovation through re-innovation. This way, the need for both management control and situatedness is met in the service innovation process.

This leads to the principle of rolling out as situated re-innovation (\#4; see table 1).

\subsection{The principle of continuous innovation}

To continue this line of argument, changes happen in the socio-material assemblages that may make the information technology unfit or obsolete as time goes by. Resources are rarely granted for continued development and static systems can led to a lack of benefits realization and even extra cost. Thus, we suggest that innovation towards beneficial socio-material assemblages needs to be continuous. The organization has to accommodate re-innovation when appropriate to assist emergence of uses because "the more humans invent, the more there is to invent" [7].

To sum up, information systems and thus digital service innovation systems are socio-material assemblages with the social and material inseparable. Beneficial service innovation towards these assemblages should therefore be organized according to the above suggested principles.

\section{Illustrating the principles}

Digital service innovation is a goal of many municipalities [9]. The challenges and ambitions of Viborg are not exceptional. Their way to success is. This section illustrates how Viborg municipality's innovative practice is aligned with the principles of digital service innovation for social care, showing that the principles are applicable in practice. Below, we illustrate this by describing the organization of the home care digital service innovation leading to usefull socio-material assemblages. The illustration is structured by the principles, and the empirical evidence is examples from the case, patchily detailing the case story described in Section 2 . However, first we establish that home care practice is socio-material.

The home care centers have complex social practices formed among others by the people involved, by traditions in the field, instructions from management, and by the citizens and their relatives. It is also a set of material practices formed by the actual place, the homes of the citizens, the commute, the tools of various kinds (including information technology), the information exchange boards, the centers, etc. None of these would function as a home care practice on its own. No doubt that home care 
service in general and each particular instance can be understood and described as socio-material assemblages.

Adding new or altering the material substance, in this case the actual screens, the software, the wire, etc., alters the existing socio-material assemblage. The social in the situations (e.g., the belief that warm hands provide the best care) also influences the assemblage and potentially alters the material. Even the service innovation process is interconnected with, and influences both, the social and material of the new assemblages (e.g., through the workshops and the positive war stories provided).

It is apparent that the practice of home care digital service is socio-material as are innovation practices.

\subsection{Mutual adaption between the social and material}

The mutual adaption between the material and social was explicit in the pilot. The immature technology was flexible enough to accommodate an experimental innovation process. For example, the technology allowed for relatively quick development and adaptions so the practitioners in the pilot did not experience destructive delays. The employees showed the necessary patience, they were flexible and managed to stay engaged. This openness allowed for experiments to be socially driven (e.g., the practitioners requested the technology to adapt in certain ways or they came up with new ideas of use potential). So, the practitioners embraced the potential and flaws of the technology and the vendor willingly adapted the technology to practice. This mutual adaption contributed to a successful pilot design, drawing on engaged and responsible practitioners' knowledge, providing mutual learning, and developing useful software. The mutual adaption during the pilot required patience from the practitioners. The speed and flexibility of the technology was an issue in the daily practice, most often sufficient, but not more. It worked out because the existing socio-material assemblage was sufficiently flexible, embracing both the technology and the difficulties it posed on the pilot project. But notice that this technology is state of the art for the time being. One could wish for technology as malleable as LEGO to improve innovation practice.

During and after the roll-out, improved versions of the system were requested by the use organization and installed without hassle. One example of the technology adapting to the existing socio-material assemblage was the implementation of a mobile version for iPads that allowed carers to make calls from anywhere. This technical adaption sparked a social adaption as the call practice changed, and it was increasingly adopted among carers. The mobile version proved flexible enough to lead to the emergence of new practices (e.g., calling the nurses). As the technological system matured it also improved, its flexibility better accommodating continued innovation. However, it could have settled the other way around with static technology and standardized uses, obstructing further innovation.

\subsection{Piloting the creation of deep insight in practice, technology, and the emergent assemblage}

The first condition is the presence of parties respectively knowledgeable of practice and technology. As described in section 2 the municipality and the vendor in collaboration attained the necessary deep insight from their respective priory knowledge and through the experimental onsite pilot project. The COPD system seemed simple, but security, availability, and protection of personal data were challenging. The use situations were delicate, involving a broad range of stakeholders.

The embeddedness of the pilot was reach through involvements of a range of practitioners as the parties took the complex nature of home care seriously. Equal participation and close collaboration became the key to success through deep it generated. Even though each party joined the collaboration to reach their own separate goals, the overall mutual interest in the project influenced their goals and a mutual interest in designing a useful solution emerged enhanced learning.

The experimental pilot soon developed an iterative nature of swift adaptions of both the social and material aspects, allowing for knowledge building about the emerging assemblage. This is the next condition for developing deep insight. Below, we detail how these activities were carried out.

To continue the progress and quality of the process, the participants need to have a feeling of flow and ease, which is supported by openness, swiftness, and agility in the collaboration. Maintaining this feeling is most difficult for the carers because it is not their core work, but rather part of involvement in the pilot. Thus, participating in the pilot must be simple for them. In this case the participants did not lose interest but felt their contribution important throughout the pilot.

The experimentation was embedded in the actual daily work as soon as the technology was sufficiently matured. Initially, the piloting home care center was introduced to the technology and asked to come up with ideas for usages. The ideas were discussed and 
took root, then suitable technology was developed, implemented in practice, tested, evaluated, and again adapted. The carers persuaded citizens to take part in the experiments, learned how to set up screens, learned how to connect to the broadband, taught the citizens, etc., and they adapted their practice accordingly so they could make the calls as arranged.

To test the system in the homes of citizens, hardware and software was installed and introduced, then experiments with tele-visits were initiated. In these, the citizens and their relatives only took part as indirect informants.

Balancing practice and experimentation can be difficult. The case shows challenges of testing and evaluation in practice (e.g., ambiguous feedback, difficulty measuring, biased data, and the intrusion into practice may be critical). Even so, embedding experimentation into practice has the benefit of providing deep insight into the actual situation, which carries potential for better solutions versus the case in traditional laboratory settings. Some examples: The need for a $100 \%$ reliable connection turned out to be technically difficult to meet in the countryside of Denmark. This would not have been revealed outside practice and even if so, the insecurity created is likely to be underestimated as a laboratory is a safe context, and the citizens involved would probably be the more resource full.

Also, the learning from practice experiments changed the practices of the carers. Turning away from the screen during virtual visits carers had to keep talking to the citizens, otherwise the citizens thought the connection was lost. They could better deliver service on time, being able to control time consumption when virtual. Negatively, overseeing medication turned out to be inapt because some citizens would cheat. Thus, improved practice had to be established.

The next and last example shows how experimenting can lead to adapting the technology. As the carers were expected to look presentable, they were distracted by an impulse to check their appearance in the "mirror" of the on-screen window showing their faces. This would not have appeared in a laboratory test as it took time for the carers to admit a problem existed. The solution was easy due to the flexible technology-minimize the window.

\subsection{Empowered, user-driven, and participatory innovation}

As described above, the carers participated in an engaged and responsible way during the pilot. They had direct access to the developers and worked with them directly on idea generation and evaluation.
They were urged to understand the technology, experiment with it, be inventive, and see the innovation potential in their work. The most engaged practitioners were driving forces towards innovation.

The participating care workers could decide on concrete aspects (e.g., proposing ideas and initiating experiments) within the limits of the pilot. Major decisions were a management matter; however, the practitioners willingly informed these decisions by putting their deep insight at management's disposal.

We saw the empowerment created a feeling of ownership, commitment, and engagement as a bonus on top of the informed innovation. As the practitioners felt safe through the empowerment, they risked being honest.

\subsection{Rolling out as situated re-innovation}

After the pilot, the manager of the innovation center in charge of the digitalization project wondered how best to roll-out the service innovation. She was skeptical towards traditional roll-outs, as she had seen many fail. She asked for a meeting with the researchers, and we suggested rolling out as reinnovation mimicking the innovation in the pilot. The idea was to create a sense of ownership in each center, as they were allowed to adapt their own practices and to suggest changes of the technology.

As mentioned above, workshops were arranged to introduce the tool and discuss its application in their work practices. The group of care workers was asked to pinpoint work tasks that could benefit from the tool and to choose potential citizens for the first televisits. Subsequently, some local super-users actively pushed their colleagues to use the system, while in other groups the system was more or less ignored until their managers came under pressure to reach the goals of the business case. Despite the roll-out as reinnovation, the centers welcomed the new digital service differently. This is not surprising as each center differs in its socio-materiality.

The initial resistance among many of the carers was often based in the changes of the relation to the citizen (less warm hands or lack of technological confidence). After a year of use, however, we interviewed former sceptics who had overcome the technical barrier and developed their own ways of being with their citizens through the tele-visit system. The system was unstable at first, but when stabilized (technology adaption) citizens (few) using it were positive (to many carers' surprise).

Apparently, the roll-out as re-innovation led to widespread integration into practice through situated experimenting in the centers. It must be mentioned that in this early phase the innovation management 
pushed hard. This concrete roll-out pushed the limits of what is possible in public practice today. However, taking the theory of social-material assemblages at face value means that time, geography, and social situations change continuously into new sociomaterial assemblage. To match this, re-innovation requires both adaptable practice and flexible information systems to reach useful fusions.

In practice though, the centers are not that different as they comply with the same laws, service goals, and procedures (e.g., documentation). Staff in the centers also have the same training and thus, to some extent, the same values. Powerful forces in their context, such as management and the policy level, are also shared. Thus, the home care centers do not differ randomly as many aspects of their assemblages are similar. So, light-way re-innovation based on the results of the pilot may be sufficient in practice to situate innovations, at least if all of the following is allowed when adapting locally: using the tool appropriately, changing the tool, using it differently, and refraining from using it. When prompting technology and its use from outside the center (e.g., management), pilot participants and vendors will of course influence the result of the adaption just as much as other forces.

\subsection{Continuous innovation enhances benefits}

In the case, we see the start of continuous innovation. After introducing the mobile version in a home care center, the staff communicated with each other and the nurses through the tele-visit system. This new use of the system reached the innovation management, and they organized to round up, evaluate, and spread the like in the organization. The super-users were chosen to be the link from management to practitioners. They took part in regular networking sessions facilitated by the innovation project manager. The sessions supported sharing stories of useful practices, braced innovative mindsets, idea generation, and skill development. Through the sessions, the local super-users could contribute to continued re-innovation. The ones we have interviewed were proud of their new role, especially the one who had come up with the idea that management and colleagues liked. The innovation process keeps rolling and the service ecosystem is extended with new actors. At the moment, the centers strive to connect to external collaborators involved in the care of the citizens, such as physiotherapists, ergonomic advisors, hospitals, and even medical general practitioners. They also explore how the actual technology can enable other services. To engage in continuous re-innovation, organizations must stay vigilant and nurse situated inventiveness. Continuing the search for new, useful practices and exploiting opportunities given will increase the likelihood of achieving benefits of the investment, even though it is not according to the initial business goals.

\section{Discussion}

Based on this exemplary research, we will discuss a few barriers for the proposed type of innovation.

Unpredictability is difficult for public organizations to handle as the regime of new public management entails clear business cases, plans, and means for control to get political or management approval. Situated re-innovation will be perceived as uncontrollable as budgets and benefits will drift

Situated innovation is difficult not only because the professional practices differ, but because they also differ in innovation capabilities. Traditional implementation skills to adopt and comply need be extended with an innovative mindset, technological curiosity, ability to collaborate across skill boundaries, and much more. It is evident that not all employees possess the desired capabilities; given the social focus, there are few digital natives and a compliance culture. Lastly, it may be challenging to guarantee equality such as identical service and data validity. Also, diverse instances of the system complicate maintenance, support, etc.

Overcoming these barriers demands courage, trust, openness, risk-taking, and willingness to learn and change one's mindset from the top level to the carer and across the involved parties. Management especially has to loosen its control in the quest for useful innovation [23], balancing control with exploring newly emerged opportunities [24].

In the light of these challenges, Viborg municipality has done well, embarking on a risky road towards improving its home care practice.

The above argued and illustrated principles express a different understanding of digital service innovation in organizations that is more effective in exploiting information technology. As we have shown through our case, a socio-material approach provides other opportunities to drive innovation of a social service system through the means of As a result, we see how the many yet small and continuously improved changes might be incremental [25] but altogether form a radically changed practice, which keeps opening up opportunities for new innovation [7].

The socio-material approach to digital service innovation may thus be characterized as an incremental process based on high user involvement, 
where the users are employees. The level of involvement goes beyond the existing service innovation methods for customer/user involvement. The employees as a collective customer in terms of the home care groups in the municipality are not only involved as a resource, co-creator, or user to test the service innovations [25], they are involved as a partner, which means they are all the three and in a continuously manner as well as having decisionmaking power. Being involved in a partnership (PPI) may help us understand why time and cost are approached differently from the usual customer/provider relationship and why they become less of an obstacle to success [8]. One can see the principles of empowerment, collaboration, and embedded iterative experiments as being in continuation of early participatory design research allowing users to experiment freely, not the least through tools they master to regain power [26].

The case is also an example of an ongoing, emerging, and extended service ecosystem [7]. It starts with service innovation, service delivery innovation, and organizational innovation [9] in relation to the digitalization of existing services. Systemic innovation, meaning collaboration with external partners [ibid.] is an issue from the start as the innovation includes an external partner with technological knowledge. Later on, the service system is further extended within and across the service organization of the municipality as nurses and ergo therapists are involved, and to external partners such as the hospitals. Another important part of this service system innovation is an ongoing alertness towards what is good home care service, which means contesting the existing assumptions (conceptual innovation) and changes in the belief systems (policy innovation) as in the case of "warm hands." All these different types of innovations are in play and involve actors at many different levels of the service ecosystem. This is important to understand in order to succeed in public service innovations of complexity.

There is still room for improvement in the case of tele-visits in Viborg municipality. The ecosystem so far has the home care centers at its core. They are at the same time service provider and service consumer, which complicates the ecosystem. The extension of the ecosystem so far is to other professional actors internal and external to the municipality.

However, citizens represent important groups of actors to be involved more actively. At present, they-care receivers and their relatives-are only involved indirectly through the service exchanges they engage in. But, the citizens are most likely also having creative input to changed or new practices.
The reasons for hesitating to involve the citizens might be their lacking resources and being subsidized receivers of services making it difficult to manage expectations. No matter the reasons, it may be argued according to socio-materiality and service innovation theory that citizen groups represent lost opportunities. A more courageous set up would therefore include such central groups of actors in the service system.

In relation to our socio-material innovation principles, we see that management is needed but in a particular fashion. Innovation management is important to supporting the service innovation process, keeping it on track, and developing the right situations and circumstances to make it happen in an ongoing way. Part of innovation management is to ensure resource integration both within the service organization of the municipality but not the least in relation to the external service partner.

On a more general level, our findings may be applied to implementation of technology in any organizational setting. Information technology often does not succeed in delivering the expected benefits when development and implementation follows more traditional approaches [27]. Continuous co-creating and situated re-innovation may provide other means to get closer to beneficial assemblages.

\section{Conclusion}

How can we understand digital service innovation in complex social situations through the lens of social-material assemblages? Our answer is that this is best understood by the developed five principles for service innovation. The principles suggest organizing innovation as continuous co-creation and re-innovation following experimental pilots. We have illustrated this by examples from a case study. The illustration indicates that the re-innovative roll-out is the biggest challenge for organizations. Imagining, organizing, and embracing this as continuous reinnovation is even more difficult in the public sector as regulations, monitoring, measuring, and top-down planning and control are widespread.

As the paper aims to start a renewed discourse on innovation in the view of technology as sociomaterial assemblages, we hope for others to continue from these first ideas.

\section{References}

[1] Andersen, K. V., and Henriksen, H. Z, "Government maturity models: Extension of the layne and lee model", Government Information Quarterly (2006), 23(2), pp. 236248. 
[2] Bohmann, T., Leimeister, J. M., and Möslein, K, "Service Systems Engineering - A Field for Future Information Systems Research," Business \& Information Systems Engineering (2014), 6(2), pp. 73-79.

[3] Stamoulis, D., Gouscos, D., Georgiadis, P., and Martakos, D, "Revisiting public information management for effective e-government services". Information Management \& Computer Security (2001), 9(4), pp. 146153.

[4] Bertot, J., Estevez, E., \& Janowski, T, "Universal and contextualized public services" Digital public service innovation framework (2016), pp. 211-222.

[5] Peters, C., Blohm, I., \& Leimeister, J. M, “Anatomy of successful business models for complex services: Insights from the telemedicine field", Journal of management information systems (2015), 32(3), pp. 75-104.

[6] Bason, C, Leading public sector innovation: Cocreating for a better society, Policy Press (2010).

[7] Lusch, R. F., \& Nambisan, S, "Service innovation: A service-dominant logic perspective" MISQ (2015), 39(1).

[8] Bygstad, B., \& Lanestedt, G, "ICT based service innovation-A challenge for project management", International Journal of Project Management (2009), 27(3), pp. 234-242.

[9] Windrum, P, "Innovation and entrepreneurship in public services" Innovation in public sector services: entrepreneurship, creativity and management (2008), 3-22.

[10] Orlikowski, W. J., and Scott, S. V, "Sociomateriality: Challenging the separation of technology, work and organization", The Academy of Management Annals (2008), 2(1), pp. 433-474

[11] Orlikowski, W., \& Scott, S. V, "The algorithm and the crowd: Considering the materiality of service innovation", MISQ (2015), 39(1), pp. 201-216

[12] Ekbia, H. R., Nardi, B., and Sabanovic, S, "On the margins of the machine: Heteromation and robotics" iConference 2015 Proceedings (2015).

[13] Orlikowski, W. J, "The sociomateriality of organisational life: Considering technology in management research", Cambridge journal of economics (2009), 34(1), pp. 125-141.

[14] Benbasat, I., and Zmud, R. W, "The identity crisis within the IS discipline: Defining and com-municating the discipline's core properties", MIS Quarterly (2003), pp. 183-194.
[15] Willcocks, L. P., and Mingers, J, Social theory and philosophy for information systems, John Wiley \& Sons Ltd. (2004).

[16] Cecez-Kecmanovic, D., Galliers, R. D., Henfridsson, O., Newell, S., and Vidgen, R, "The sociomateriality of information systems: Current status, future directions", MISQ (2014), 38(3), pp. 809-830.

[17] Wagner, E. L., Newell, S., and Piccoli, G, "Understanding project survival in an ES environment: A sociomaterial practice perspective, Journal of the Association for Information Systems (2010) 11(5), 276.

[18] Suchman, L, Human-machine reconfigurations: Plans and situated actions, Cambridge University Press (2007).

[19] Wynn Jr, D., \& Williams, C. K, "Principles for conducting critical realist case study research in information systems", Mis Quarterly (2012), 36(3), pp. 787-810.

[20] Mingers, J, "Realizing information systems: critical realism as an underpinning philosophy for information systems", Information and organization (2004), 14(2), pp. 87-103.

[21] Bødker, K., Kensing, F., and Simonsen, J, Participatory IT design: Designing for business and workplace realities, MIT press (2009).

[22] Nylén, D., \& Holmström, J, "Digital innovation strategy: A framework for diagnosing and improving digital product and service innovation", Business Horizons (2015), 58(1), pp. 57-67.

[23] Ciborra, C, The labyrinths of information: Challenging the wisdom of systems. New York: Oxford University Press Inc. (2002).

[24] Tjornehoj, G., \& Mathiassen, L, "Between control and drift: negotiating improvement in a small software firm", Information Technology \& People (2008), 21(1), pp. 69-90.

[25] Nicolajsen, H. W., Sørensen, F., \& Scupola, A, "The Potential of Workshops vs Blogs for User Involvement”, Service Innovation. International Journal of E-Services and Mobile Applications (IJESMA) (2016), 8(4), pp. 1-19.

[26] Bansler, J. P, "Systems development research in Scandinavia: Three theoretical schools", Scandinavian J. Inf. Systems (1989), 1(1), p. 1.

[27] Kim, H. W., \& Kankanhalli, A, "Investigating user resistance to information systems implementation: A status quo bias perspective", MIS quarterly (2009), 33(3), pp. 567-582. 